\title{
Coupling of Solvent Extraction and Ultrasonic Waves for Regeneration of Spent Activated Carbon after Treatment of Polluted Air with Toluene Vapor
}

\author{
Elham F. Mohamed (Corresponding author) \\ Air Pollution Department, Division of Environmental, \\ Research National Research Centre \\ 33 EL Bohouth St., Dokki, Giza, P.O.12622, Egypt
}

Tel.: 202-3371362Ｅ-mail address: elham_farouk0000@yahoo.com

\begin{abstract}
Waleed H. Shetaya
Air Pollution Department, Division of Environmental, Research National Research Centre

33 EL Bohouth St., Dokki, Giza, P.O.12622, Egypt

Tel.: 202-3371362Ｅ-mail address: waleed.shetaya@gmail.com
\end{abstract}

\begin{abstract}
Asmaa El-Mekawy
Air Pollution Department, Division of Environmental,

Research National Research Centre

33 EL Bohouth St., Dokki, Giza, P.O.12622, Egypt

Tel.: 202-3371362_E-mail address: asmaamekawy75@gmail.com
\end{abstract}

\begin{abstract}
Alia A. Shakour
Air Pollution Department, Division of Environmental, Research National Research Centre

33 EL Bohouth St., Dokki, Giza, P.O.12622, Egypt

Tel.: 202-3371362Ｅ-mail address: aliashakour@gmail.com
\end{abstract}


Gamal Awad

\author{
Chemistry of Natural and Microbial Products Department, \\ Division of Pharmaceutical Industries, National Research Centre \\ 33 EL Bohouth St., Dokki, Giza, P.O.12622, Egypt \\ Tel.: 202-3371362 E-mail address: awad_gamal7@yahoo.fr
}

\begin{abstract}
Received: March 5, 2017 Accepted: April 6, 2017 Published: April 7, 2017
Doi: 10.5296/jab.v5i2.10867ＵRL: http://doi.org/10.5296/jab.v5i2.10867
\end{abstract}

\begin{abstract}
A batch process was used to evaluate the potential of regeneration of spent activated carbon (AC) by solvent extraction technique with synergetic to ultra-sonication. Experiments were undertaken as a function of the initial concentration of toluene. Freundlich and Langmuir models were used to study the adsorption isotherms and the data well fitted the Langmuir expression. The maximum adsorption capacities of toluene were found to be $0.108 \mu \mathrm{g} / \mathrm{g}$ activated carbon for Type-I Langmuir. Extraction of the used AC by both methanol solvent and ultrasonic radiation yielded up to $95 \%$ reactivation of the spent $\mathrm{AC}$ in the first run. Nearly up to $88 \%$ recovery of activity could be achieved after further regeneration and reusing of the spent AC. The results indicate that the coupling of solvent extraction with ultrasonic waves in the AC treatment is comparable and perhaps superior to the conventional regeneration techniques in many cases. This is mainly due to the single step process applied which is less energy consuming; in addition to the nearly comprehensive recovery of the adsorptive capacity of spent AC.
\end{abstract}

Keywords: Spent activated carbon, Regeneration, Solvent extraction, Ultra sonication, Treatment

\title{
1. Introduction
}

Volatile organic compounds (VOCs) are radiated as gasses from specific solids or fluids. VOCs in the urban environment for the most part emerge from the powers utilized as a part of engine vehicles. VOCs incorporate an assortment of chemicals, some of which may have short-and long haul antagonistic well-being impacts. VOCs are of worry as both indoor air toxins and as outdoor air contaminations. In ambient air, VOC is connected with discharges from a scope of sources, for example, engine vehicle debilitate, petroleum refineries, plastics and the utilization of solvents (Ye et al., 2014; US EPA, 2012, 2014). The sources and levels of the VOCs in indoor air shift contingent upon the kind of building. Ignition especially tobacco smoking, additionally laser imprinting on paper or photocopying firmly influence the indoor levels of VOCs (Wheeler et al., 2013). In any case, thinks about have found that levels of a few organics normal 2 to 5 times higher inside than outside (Weisel et al., 2008). In 
addition, as a great many people invest the lion's share of energy inside, the indoor introduction assumes a critical part in the general individual presentation and along these lines in any well-being hazard evaluation. Activated carbon adsorption is the most effective technology for removing trace contaminants from both air and water (Mohamed et al., 2011, 2015, 2016a). On one hand, the utilization of activated carbons as adsorbents is restricted by the issue related to their recovery. In this point of view, distinctive option recovery strategies are attractive to beat these sorts of issues (Mohamed et al., 2016b). In this context, solvent extraction regeneration appears as interest method to clean spent activated carbon, since their application could result in a cost-effective process for activated carbon recovery (Ma et al., 2016). The present study aims to regenerate the used activated carbon via solvent extraction process using methanol under ultrasonic radiation, and also to investigate the efficiency of the regenerated activated carbon for Toluene gas removal.

\section{Experimental}

\subsection{Materials}

Granular activated carbon (S23) from coconut shell was used (the same type of that used in charcoal tube air sampling). The particle size of the used ACs is in the range of 0.2-0.4 mm. The adsorbate used to challenge the adsorbents was toluene (Sigma-Aldrich, $>99 \%$ purity) as the representative VOC because it is one of the most common VOCs in the workplace and is one of the major and most often reported indoor organic vapors. It is often considered a representative for the VOC group in several studies involving the testing of AC materials. Other materials were also used as ethanol $\left(\mathrm{C}_{2} \mathrm{H}_{6} \mathrm{O}\right)$, hydrogen chloride $(\mathrm{HCl})$, sodium hydrogen carbonate $\left(\mathrm{NaHCO}_{3}\right)$, sodium carbonate $\left(\mathrm{Na}_{2} \mathrm{CO}_{3}\right)$ and sodium hydroxide $(\mathrm{NaOH})$.

\subsection{Physical and Chemical Properties of Carbons}

\subsubsection{Specific Surface Area and Pore Volume}

The surface physical properties of the AC were characterized with a Micromeritics ASAP 2020 , using Nitrogen $\left(\mathrm{N}_{2}\right)$ as a desorbate at $77 \mathrm{~K}$. The specific surface area (SBET) was calculated from the adsorption branch of $\mathrm{N}_{2}$ isotherm using the Brunauer-Emmett-Teller (BET) method in a relative vapor pressure ranging from relative pressure of 0.01 to 0.2 (Stephen et al., 1938). Pore size distribution was obtained from desorption branch of $\mathrm{N}_{2}$ isotherm by the Barrett-Joyner-Halenda $(\mathrm{BJH})$ method. The total porous volume was estimated from the adsorption. The Horvath-Kawazoe method was applied to analyze the pore size distribution, which was expected to be suitable for porous carbons with predominant microporous of width below $1 \mathrm{~nm}$.

\subsubsection{Surface Group Determination}

a. The thermogravimetric analysis (TGA)

The thermogravimetric analyses (TGA) give information about the weight change under heat treatment then the amount of the volatilized species. Samples (about $20 \mathrm{mg}$ ) were heated from 100 to $900^{\circ} \mathrm{C}$ under nitrogen flow at a heating rate of $10^{\circ} \mathrm{C} / \mathrm{min}$ in a Thermo balance, SDT Q 600, TA Instruments. 
b. Boehm titration method

The acid/base properties of AC were determined by the classical Boehm titration method (Boehm, 1994). One gram of carbon sample was placed in $50 \mathrm{ml}$ of $0.05 \mathrm{~N}$ of the following solutions: sodium hydroxide $(\mathrm{NaOH})$, sodium carbonate $\left(\mathrm{Na}_{2} \mathrm{CO}_{3}\right)$, sodium bicarbonate $\left(\mathrm{NaHCO}_{3}\right)$, and hydrochloric acid $(\mathrm{HCl})$. The vials were sealed and agitated for $24 \mathrm{hr}$ and then filtered; $5 \mathrm{ml}$ of the filtrate was pipetted, and the excess base or acid was titrated with $\mathrm{HCl}(0.1 \mathrm{~N})$ or $\mathrm{NaOH}(0.1 \mathrm{~N})$, respectively. The number of acidic sites was determined under the assumption that $\mathrm{NaOH}$ neutralizes carboxylic, lactonic, and phenolic groups; and $\mathrm{Na}_{2} \mathrm{CO}_{3}$ neutralizes carboxylic and lactonic groups; and $\mathrm{NaHCO}_{3}$ neutralizes only carboxylic groups. The number of basic sites was calculated from the amount of hydrochloric acid that reacted with the carbon.

\subsubsection{Analysis SEM / EDX}

Scanning Electron Microscopy (SEM) and Energy Dispersive X-ray analysis (EDX) were used to observe the structural morphology and composition of activated carbon.

\subsection{Adsorption Equilibrium Experiments.}

Batch adsorption isotherms were performed using the bottle point method, as described elsewhere (Brosillon et al., 2001). A schematic diagram of the experimental system used to determine the adsorption performance was represented in Figure 1. Activated carbon samples were introduced into the angled tube $(0.5 \mathrm{~g})$ of the batch glass contactor $(1 \mathrm{~L})$. Then, a known volume of liquid toluene was injected through a septum into each adsorption chamber at 300 $\mathrm{K}$ and $101 \mathrm{kPa}$, leading to a desired initial toluene concentration after its complete evaporation. The AC was put into contact with the air/ toluene mixture when all the liquid had evaporated. Adsorption chambers were stirred until equilibrium was reached. When air samples have been obtained by trapping on a solid sorbent, it is necessary to desorb them with a liquid solvent, suitable for injection into the HPLC using a C18 reverse phase column (ProntoSIL C18 AQ) and a Varian ProStar 310 UV/Vis detector (wavelength $257 \mathrm{~nm}$ ). It is important to choose a solvent that will not interfere with detection of the analyte (s). The solvent must also be capable of stripping the analyte from the sorbent with a high degree of efficiency. When the adsorption test was completed, the activated carbon was disposed in 5 $\mathrm{ml}$ vial contained $5 \mathrm{ml}$ of methanol and then place in ultrasonic bath at $40{ }^{\circ} \mathrm{C}$ for 60 minutes to desorb VOC into methanol. The desorbed toluene analyzed by HPLC. The adsorption capacity $(\mathrm{Q})$ was then calculated by equation 1 .

$$
\mathbf{Q}=\frac{\mathbf{M}_{\mathrm{ads}}}{\mathbf{M}_{\mathrm{AC}}}
$$

Where $\mathrm{Q}$ is activated carbon adsorption capacity ( $\mu \mathrm{g} \mathrm{VOC} / \mathrm{g} \mathrm{AC}$ ), $\mathrm{M}_{\text {ads }}$ is adsorbed mass of VOCs ( $\mu \mathrm{g}$ VOC), and $\mathrm{M}_{\mathrm{AC}}$ is the mass of activated carbon ( $\mathrm{g} \mathrm{AC}$ ).

Plotting the solid-phase concentration Q against the gas-phase concentration graphically 


\section{Macrothink

depicts the equilibrium adsorption isotherm. Another aspect that concerned us was the effectiveness of extraction method on the regeneration of the adsorption capacity of the GAC. Thus, the treated GAC was reused to adsorb toluene in the same manner. The GAC adsorption/solvent treatment process was repeated for two runs.

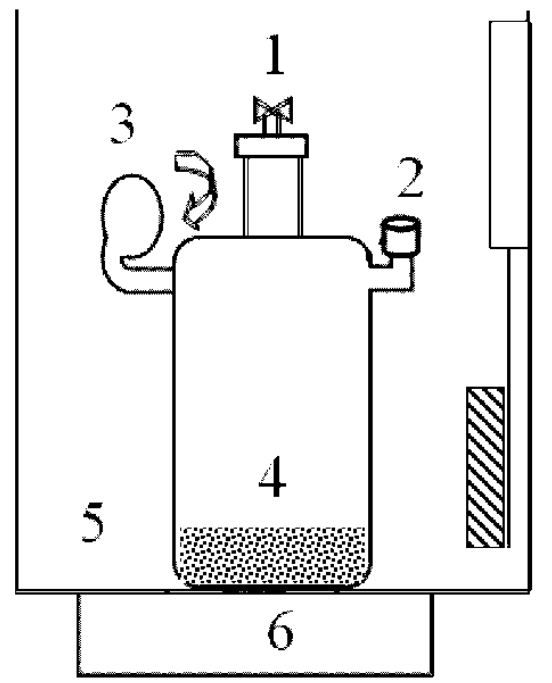

Figure 1. Experimental device for adsorption isotherm determination: (1) valve for gas sampling, (2) liquid injection septum, (3) angled tube containing the adsorbent, (4) bottle contactor, (5) thermostatic bath and (6) stirring system.

\subsection{Calculation of Regeneration Efficiency}

The regeneration efficiency is based on recovery rate of the adsorption capacity of activated carbon. The regeneration efficiency is signed as RE \% Eq. (2). The original adsorption capacity (Qv) of the AC for toluene adsorbed from air sample by per unit weight of AC at the end of contact. The adsorption capacity of regenerated AC (Qr) was considered to be the quantity of the same adsorbates adsorbed from air sample per unit weight of regenerated $\mathrm{AC}$ at the end of contact.

$$
\mathrm{RE} \%=\frac{\mathrm{Qr}}{\mathrm{Qv}} \times 100
$$

\subsection{Theoretical Background}

\subsubsection{Langmuir Model}

The Langmuir model assumes uniform energies of adsorption onto the surface and no 
transmigration of adsorbate in the plane of the surface. The Langmuir equation may be written as the following (Eq.3):

$$
q_{e}=\frac{q_{m} b C_{e}}{l+b C_{e}}
$$

Where $q_{\mathrm{e}}$ is the amount of solute adsorbed per unit weight of adsorbent at equilibrium (mg. $\left.\mathrm{g}^{-1}\right), C_{\mathrm{e}}$ is the equilibrium concentration of the solute in the bulk (mg.L $\left.{ }^{-1}\right), q_{\mathrm{m}}$ is the maximum adsorption capacity ( $\mathrm{mg}^{-\mathrm{g}^{-1}}$ ), and $b$ is the constant related to the free energy of adsorption (L. $\mathrm{mg}^{-1}$ ). Eq. (2) can be linearized to four different linear forms as shown in Table 1.

\subsubsection{Freundlich Model}

The Freundlich equation (Eq.4) can be written as:

$$
q_{e}=K_{F}\left(C_{e}\right)^{n}
$$

Where $K_{\mathrm{F}}$ is a constant indicative of the relative adsorption capacity of the adsorbent (mg. $\mathrm{g}^{-1}$ ) and $n$ is a constant indicative of the intensity of the adsorption.

The Freundlich expression is an exponential equation and therefore, assumes that as the adsorbate concentration increases, the concentration of adsorbate on the adsorbent surface also increases. The linear form of the Freundlich isotherm is shown in Table 1.

\begin{tabular}{|c|c|c|c|}
\hline Isotherm model & Equation & Linear form & Plot \\
\hline Freundlich & $q_{e}=K_{F}\left(C_{e}\right)^{n}$ & $\ln q_{\mathrm{e}}=\ln K_{\mathrm{F}}+\frac{1}{n} \ln C_{\mathrm{e}}$ & $\ln \mathrm{q}_{\mathrm{e}} \mathrm{vs} \cdot \ln C_{\mathrm{e}}$ \\
\hline Langmuir-1 & & $\frac{1}{q_{\mathrm{e}}}=\frac{1}{b q_{\mathrm{m}}} \frac{1}{C_{\mathrm{e}}}+\frac{1}{q_{\mathrm{m}}}$ & $\frac{1}{q_{\mathrm{e}}}$ vs. $\frac{1}{C_{\mathrm{e}}}$ \\
\hline Langmuir-2 & & $\frac{C_{\mathrm{e}}}{q_{\mathrm{e}}}=\frac{1}{q_{\mathrm{m}}} C_{\mathrm{e}}+\frac{1}{q_{\mathrm{m}} b}$ & $\frac{C_{\mathrm{e}}}{q_{\mathrm{e}}}$ vs. $C_{\mathrm{e}}$ \\
\hline
\end{tabular}

Table 1. Isotherm models and their linear forms 
Langmuir-3

$$
q_{e}=\frac{q_{m} b C_{e}}{I+b C_{e}} \quad q_{\mathrm{e}}=-\frac{1}{b} \frac{q_{\mathrm{e}}}{C_{\mathrm{e}}}+q_{\mathrm{m}} \quad q_{\mathrm{e}} \text { vs. } \frac{q_{\mathrm{e}}}{C_{e}}
$$

\subsubsection{Model Validation}

In this research, Langmuir and Freundlich equations were used to model the adsorption isotherms for toluene. The experimental data were fitted to the model using a non-linear regression using Microsoft Office Excel 2007 solver. The coefficient of determination, $\mathrm{R}^{2}$, was calculated to give a measure the variability attributed to the models. In addition to $\mathrm{R}^{2}$, the mean absolute relative errors (MAREs) between the predicted and experimental values (Eq. 5) (Kaya \& Kahyaoglu, 2005) and Fisher parameter (Eq. 6) were used to evaluate the good fit of each model. The best model selected for the experimental data is the one that gives the highest value of the Fisher parameter and minimum MARE criterion (Quiñones \& Guiochon, 1996).

$$
\begin{aligned}
& \text { MARE }=\frac{100}{N} \sum_{i=1}^{n}\left|\frac{\left(q_{\mathrm{ex}, i}-q_{t, i}\right)}{q_{\mathrm{ex}, i}}\right| . \\
& F_{\mathrm{calc}}=\frac{(n-1) \sum_{i=1}^{n}\left(q_{\mathrm{ex}, i-\mathrm{m}} q_{\mathrm{ex}}\right)^{2}}{(n-1) \sum_{i=1}^{n}\left(q_{\mathrm{ex}, i}-q_{t, i}\right)^{2}}
\end{aligned}
$$

Where $\mathrm{mq}_{\mathrm{ex}}$ is the mean value of the experimental data, $q_{\mathrm{ex}, i}$, are the experimental data, $l$ is the number of adjusted parameters of the model, and $n$ is the number of data points.

\section{Results and discussion}

\subsection{Nitrogen Adsorption and Desorption Isotherms}

The adsorption/desorption isotherms for nitrogen of AC S23 using an automatic physisorption analyzer at a temperature of $77 \mathrm{~K}$ are shown in Figure 2. According to the IUPAC classification, the curve shows a typical Type I isotherm with a well-shaped sharp slope at the low relative pressure which develop to an asymptote at elevated pressure values. The type I isotherm strongly suggests the presence of microporous adsorbents with small external surface at relatively low pressure of $<0.12$. The textural characteristics of the activated carbon are reported in Table 2. The surface area of BET, external and microporous surface areas, micropores and total pore volume, and pore size diameter are collectively important due to their close link to the adsorptive capacities (Allwar et al., 2008). Figure 3 shows the pore size distributions of activated carbon which reached a maximum level at $<2$ $\mathrm{mm}$ pore diameter indicating a microporous structure. The micropore diameters ranged from 0.8 to $1 \mathrm{~mm}$ suggesting almost negligible mesoporosity of the activated carbon (S23). 


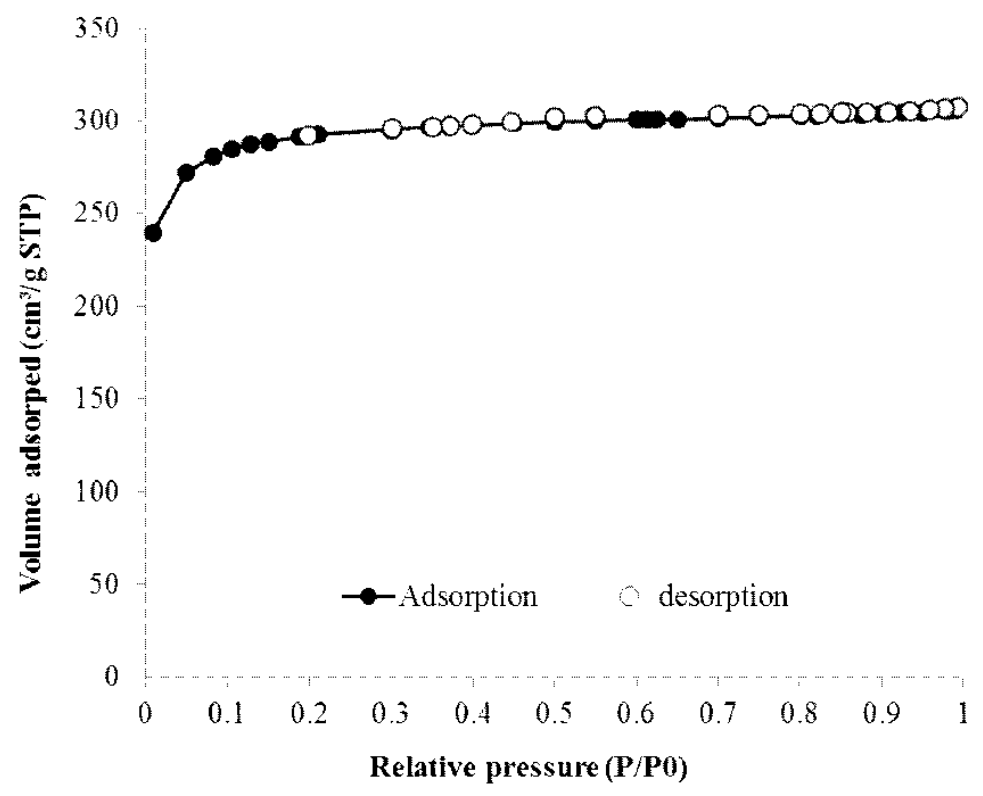

Figure 2. The adsorption/desorption isotherms for nitrogen on the activated carbon at a temperature of $77 \mathrm{~K}$.

Table 2. The textural characteristics of the used activated carbon

Activated carbon sample

Origin

Specific surface

Microporous volume

Mesoporous volume

Pore size diameter

Volume weight mean diameter: $\mathrm{d}_{43}$

(Granulometric analysis)

Apparent density

\section{Coconut}

$\mathrm{m}^{2} \cdot \mathrm{g}^{-1}$

$\mathrm{cm}^{3} \cdot \mathrm{g}^{-1}$

$\mathrm{cm}^{3} \cdot \mathrm{g}^{-1}$

0.04

$\AA$

17

$\mu \mathrm{m}$

447

kg. $\mathrm{m}^{-3}$

1013 


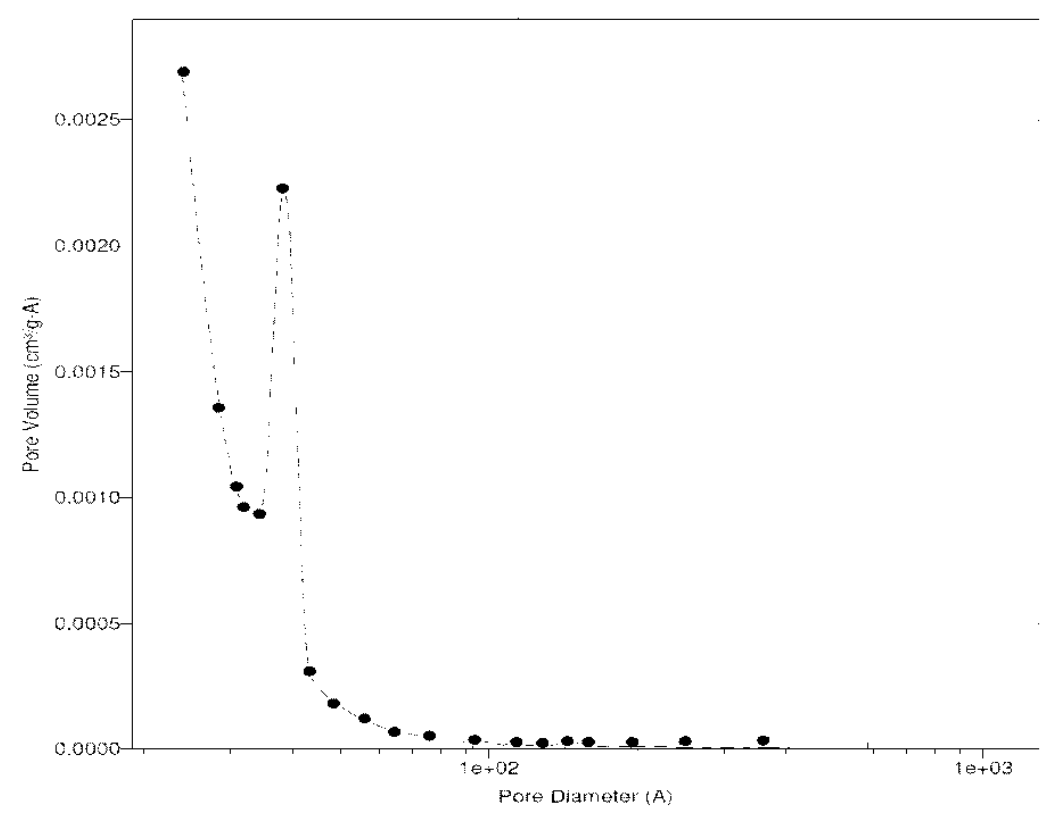

Figure 3. Pore size distributions of the used activated carbon

\subsection{Surface Morphology of Activated Carbon}

The scanning electron macrographs of the external morphology of the AC in Figure 4 conspicuously show the numerous cavities in its external surface. The elemental composition of the activated carbon was determined by the EDX analysis. Figure 5 shows the main peaks of oxygen and carbon in granular AC sample while its elemental composition percentages are given in Table 3.

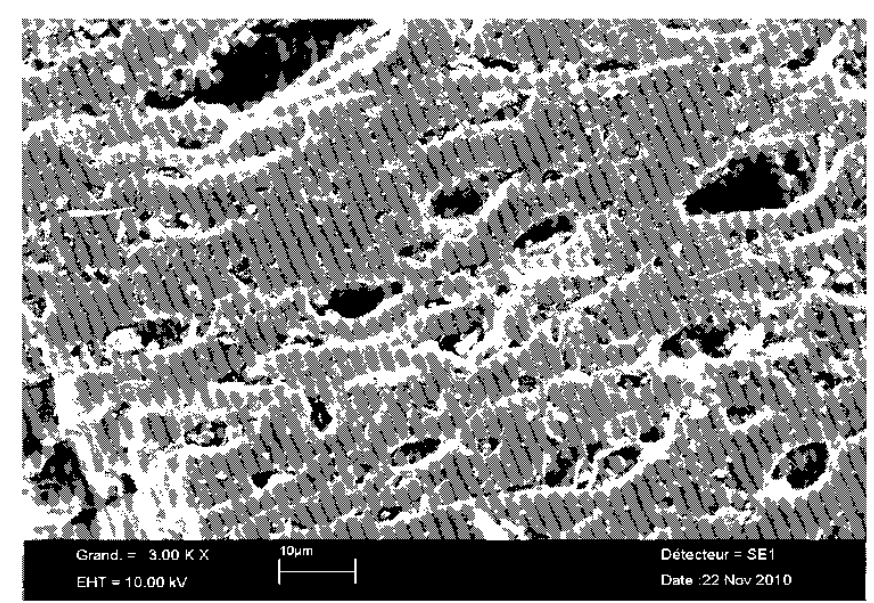

Figure 4. Structural morphology of activated carbon magnitude of 3000x 


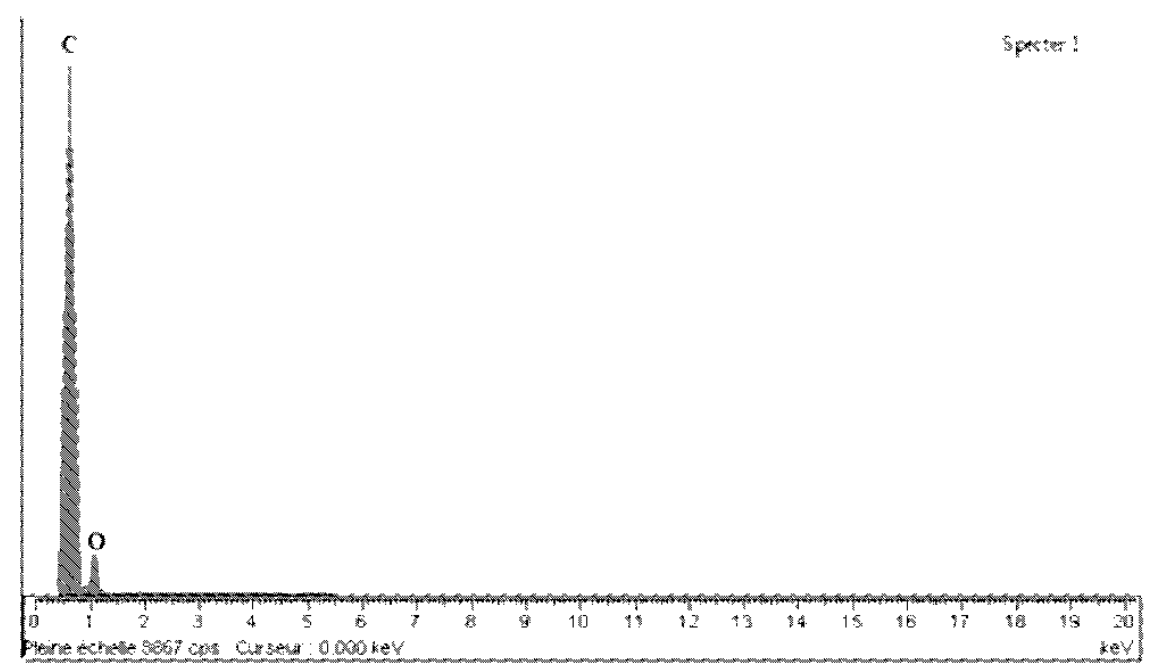

Figure 5. Energy dispersive X-ray microanalyses (EDX) analysis of the AC.

Table 3. EDX elemental composition of the granular activated carbon

Sample Composition

$\mathrm{C}$

$\mathrm{Wt} \% \quad \mathrm{At} \% \quad \mathrm{Wt} \% \quad * \mathrm{At} \%$

$\begin{array}{lllll}\text { Granular activated } & 95.20 & 96.35 & 4.80 & 3.65\end{array}$
$\mathrm{O}$

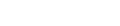

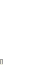




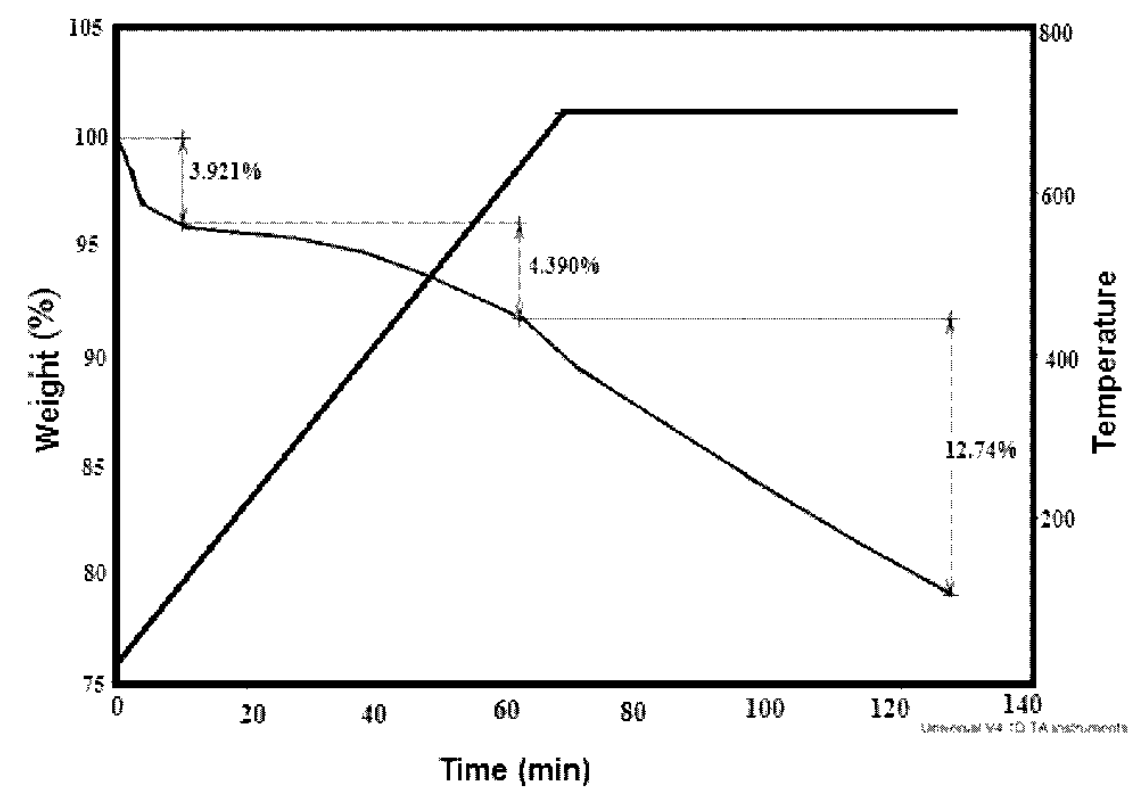

Figure 6. Thermogravimetric analysis curves for activated carbon

\subsection{Boehm Titration Method}

The acid/base properties of AC are shown in Table 4. Activated carbons are basic in nature and normally contain high content of basic groups (c. $0.98 \mathrm{mmol} \mathrm{g}^{-1}$ ). Basic groups in AC noticeably increase the adsorption of aromatic compounds, in particular, through the formation of an electron acceptor and/or donor complexes (Haydara et al., 2003). Results showed that the total AC content of acidic groups is around $0.2 \mathrm{mmol} \mathrm{g}^{-1}$.

Table 4. The acid/base groups ( $\mathrm{mmol} \mathrm{g}^{-1}$ ) of the activated carbon determined by Boehm titration

Carboxylic group Lactonic group Phenolic group Total acidic sites Total basic sites

$\begin{array}{llll}0.09 & 0.21 & 0.30 & 0.98\end{array}$

\subsection{Equilibrium Adsorption Isotherm}

The adsorption isotherm describes the distribution of the adsorbed molecules between gas and solid phases at equilibrium. The capacity of adsorption depends mainly on the properties of both the adsorbent and the adsorbate; therefore, adsorption isotherms are indispensable to correlate adsorption equilibrium data for the adsorbent materials characterization and for designing the industrial gas adsorption process. The adsorption isotherm of toluene is shown in Figure 7. The isotherm indicates the L-type which reflects a relatively high affinity 


\section{Macrothink}

between toluene and activated carbon. It is obvious from Figure 7 that there is a direct positive relationship between the adsorption capacity and the inlet concentration until it leveled off at higher concentrations. The maximum adsorption capacity was determined to be $0.108 \mu \mathrm{g}$ of toluene per gram of activated carbon.

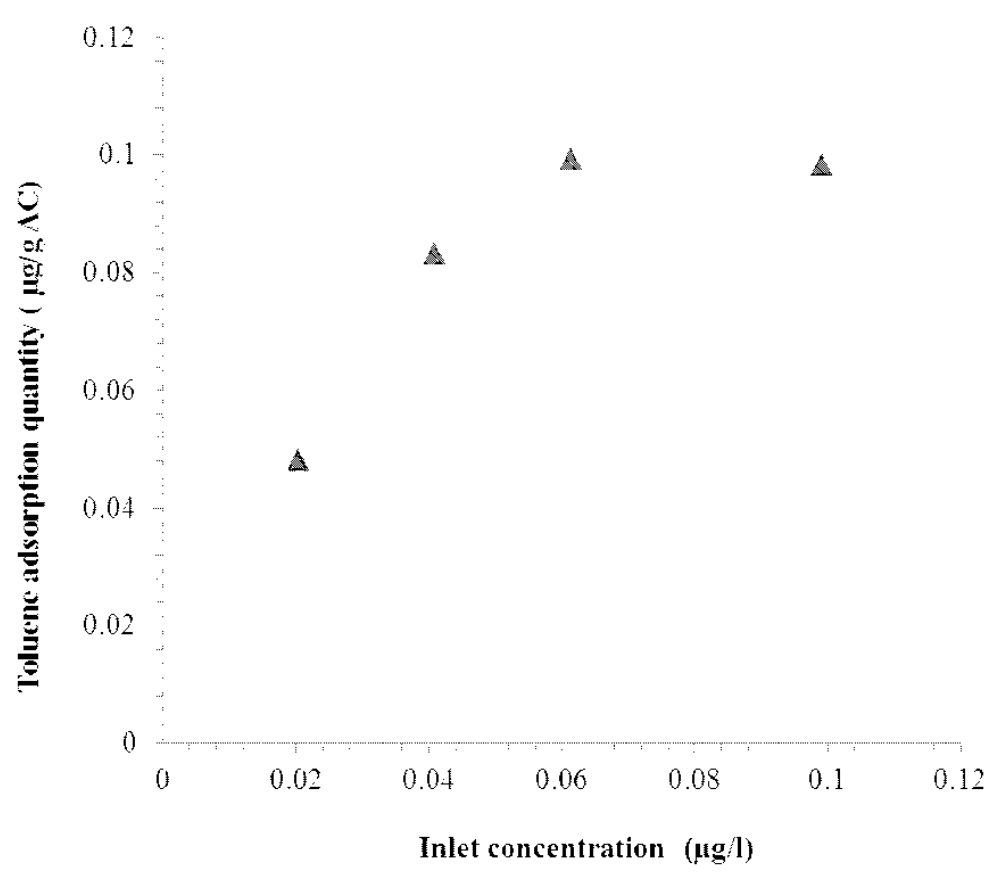

Figure 7. The adsorption isotherm of toluene vapor at $25^{\circ} \mathrm{C}$ onto granular activated carbon

Fitting isotherm data to commonly employed models is essential to find a suitable expression that can be used for design purposes. Freundlich and Langmuir models are frequently applied to interpret the experimental data of adsorption isotherms. Langmuir isotherm equation can be expressed linearly in four forms (Table 1). A trend line was plotted between experimental and observed data as shown in Figure 8. It can be clearly observed from these figures that Langmuir isotherms well-fitted the adsorption of toluene on the AC indicating that monolayer surface coverage was achieved in the studied concentration intervals. The calculated parameters in Table 5 show that different Langmuir constants produced by different Langmuir equations. This was indicated by the variations in errors specific to each corresponding linearization mode. Table 5 also shows that Type-I linearized Langmuir equation exhibited higher correlation coefficient $\left(\mathrm{R}^{2}=0.99\right)$ in comparison to other Langmuir equations which means Type 1 Langmuir model can be used to represents the experimental data. The adsorption capacity of toluene was $0.108 \mu \mathrm{g} / \mathrm{g}$ AC for Type-I Langmuir. The Langmuir model describes monolayer adsorption of adsorbate onto a homogeneous adsorbent surface (Dabrowski, 2001). Freundlich model did not give a good coefficient of determination (Table 5) which indicates that Freundlich model are not able to describe equilibrium data and there was no multilayer formation of toluene on the activated carbon 
surface. These results coincided with the textural characteristics of the activated carbon (Table 2) where, AC used has $0.49 \mathrm{~cm}^{3} \cdot \mathrm{g}^{-1}$ microporous volume and only $0.04 \mathrm{~cm}^{3} \cdot \mathrm{g}^{-1}$ mesoporous volume.

Table 5. Linearized parameters of toluene adsorption isotherm onto granular activated carbon

\begin{tabular}{|c|c|}
\hline Parameters & model \\
\hline & Langmuir (1) \\
\hline $\mathrm{q}_{\max }$ & 0.108 \\
\hline $\mathrm{K}$ & 165.65 \\
\hline \multirow[t]{2}{*}{$\mathrm{R}^{2}$} & 0.995 \\
\hline & Langmuir (2) \\
\hline $\mathrm{q}_{\max }$ & 0.124 \\
\hline $\mathrm{K}$ & 97.502 \\
\hline \multirow[t]{2}{*}{$\mathrm{R}^{2}$} & 0.976 \\
\hline & Langmuir (3) \\
\hline $\mathrm{q}_{\max }$ & 0.118 \\
\hline $\mathrm{K}$ & 112.359 \\
\hline \multirow[t]{2}{*}{$\mathrm{R}^{2}$} & 0.881 \\
\hline & Freundlich \\
\hline $\mathrm{K}$ & 0.252 \\
\hline $\mathrm{n}$ & 0.373 \\
\hline $\mathrm{R}^{2}$ & 0.823 \\
\hline
\end{tabular}




\section{Macrothink

To examine the validity of the Langmuir model, the mean absolute relative errors (MAREs) between the predicted and experimental values and the Fisher parameter were calculated (Table 6). The MAREs for Type-I, Type-II and Type-III were less than $10 \%$ which indicates the suitability of the models to describe equilibrium data with minimum error. On the contrary, the MAREs for the linearized Freundlich model was $21.23 \%$ indicating that the Freundlich model is not the best choice to fit the equilibrium data; this was also supported by the lower correlation coefficient values further confirming the inability to use this type of linearization.

Table 6. Comparison between the mean absolute relative errors (MAREs) and Fisher parameter between the predicted and experimental values of Langmuir models (Type-I, Type-II and Type- III) and Freundlich model

Parameters model

Fcalc

K

97.502

Fcalc

8.690

MARE 
Frendluish

K

g

Fcalc

MARE
0.252

0.373

0.775

21.225

Several models have been used to describe the experimental data of adsorption isotherms. The Langmuir and Freundlich models are the most frequently employed. The analysis of the isotherm data by fitting them to different isotherm models is an important step to find a suitable model that can be used for design purposes. Langmuir isotherm equation can be linearized into four forms (Table 1). A plot was drawn between experimental and observed data as shown in Fig.8. It can be seen from these figures that Langmuir isotherms expressed relatively well the adsorption of toluene on the $\mathrm{AC}$ indicating that monolayer surface coverage is reached in the concentration intervals studied. The calculated parameters are shown in Table 5, it can be observed that, different linear Langmuir equations show different Langmuir constants, as indicated by variation in errors, specific to the corresponding mode of linearization.It was observed from table 5 that Type-I linearized Langmuir equation showed higher correlation coefficient $\left(\mathrm{R}^{2}=0.995\right)$ than that of the other linearized Langmuir equations indicating that Type 1 linearized Langmuir isotherm represents the experimental data well. The adsorption capacity of toluene was found to be $0.108 \mu \mathrm{g} / \mathrm{g}$ AC for Type-I Langmuir. The Langmuir adsorption model describes monolayer adsorption of adsorbate onto a homogeneous adsorbent surface. Freundlich model did not give a good coefficient of determination (Table 5) which indicates that Freundlich model are not able to describe equilibrium data and there was no multilayer formation of toluene on the activated carbon surface. These results coincided with the textural characteristics of the activated carbon (Table 2) where, AC used has $0.49 \mathrm{~cm}^{3} \cdot \mathrm{g}^{-1}$ microporous volume and only $0.04 \mathrm{~cm}^{3} \cdot \mathrm{g}^{-1}$ mesoporous volume. 


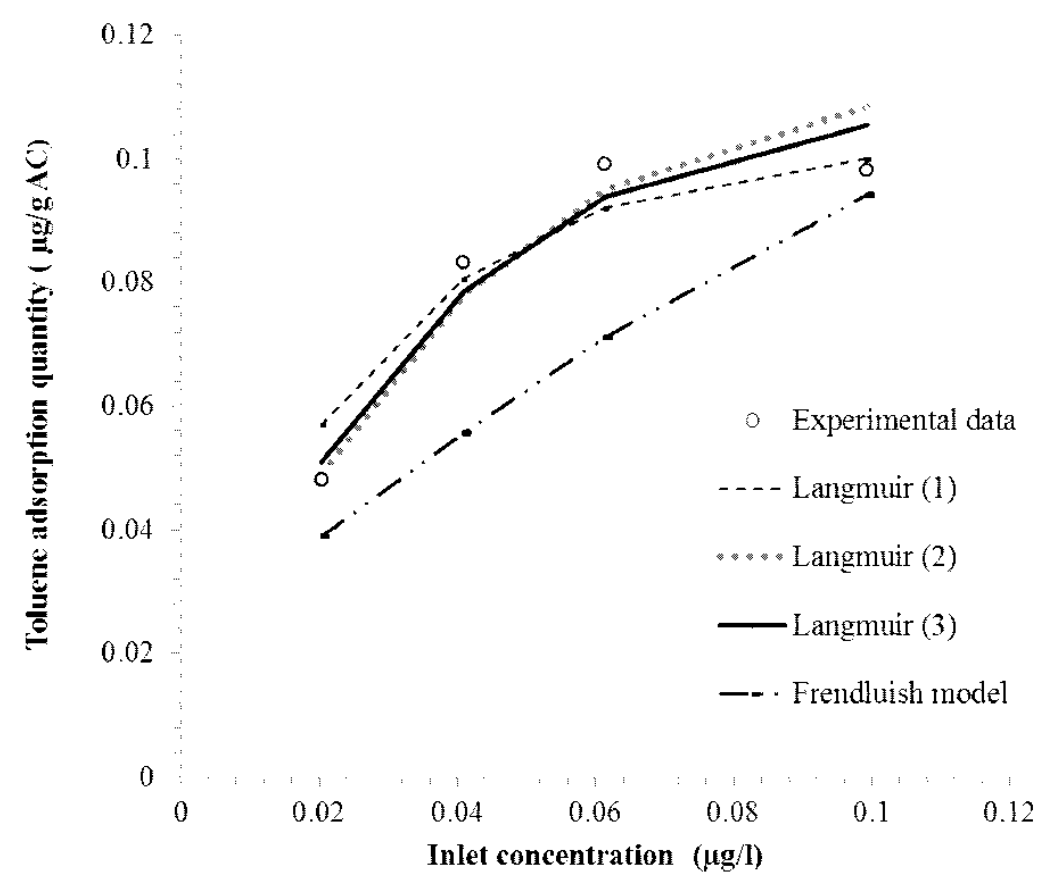

Figure 8. Langmuir and Freundlich linearized isotherm models for toluene adsorption onto granular activated carbon

\subsection{Regeneration Efficiency and Reused of the Activated Carbon}

The reused of the activated carbon after methanol/ultrasonic regeneration is shown in Figure 9. Results illustrate that the coupling of methanol extraction and ultrasonic technology is a promising alternative option to recover the used AC. The synergetic coupling of methanol extraction and ultra-sonication yielded up to $95 \%$ reactivation of spent $\mathrm{AC}$ in the first run. About up to $88 \%$ recuperation of activated carbon activity could be accomplished in the second recovery of spent AC. This result agrees with that finding of literature (Li et al., 2016) who reported $100 \%$ regeneration efficiency of AC after only one cycle, and $73 \%$ after a total of 50 cycles using $n$-octane as a regenerating solvent. Several authors (Eshtiaghi et al., 2012; Lv et al., 2012; Guilane \& Hamdaoui, 2016) demonstrated the effectively of different solvent extraction in activated carbon regeneration. 


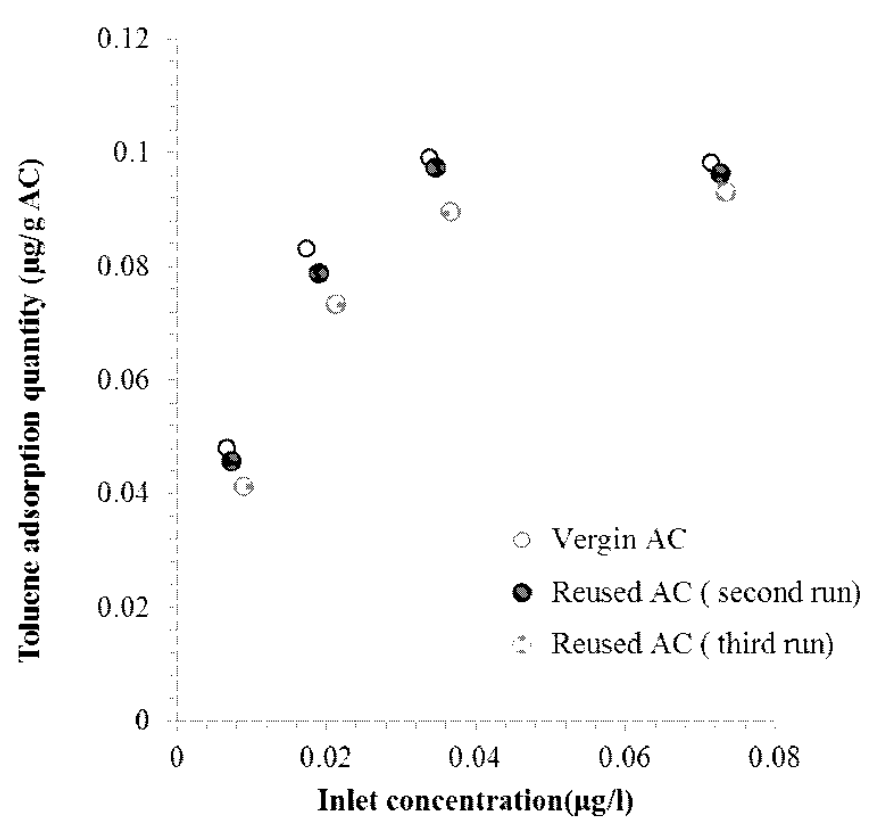

Figure 9. Reused of activated carbon after using solvent extraction and ultrasonic regeneration for toluene adsorption

\section{Conclusions}

The present investigation focused on the adsorption properties of toluene gas onto activated carbon in batch process. Comparing the mean absolute relative errors (MAREs) and the Fisher parameter between the predicted and experimental values indicated a $10 \%$ difference between experimental and calculated values for Langmuir models (Type-I, Type-II and TypeIII) and the MAREs was $21.23 \%$ for Freundlich model. It was concluded that the Langmuir (Type-I) isotherm model fit better than the Freundlich isotherm model for toluene gas adsorption. The maximum adsorption capacities were found to be $0.108 \mu \mathrm{g}$ of toluene per gram of activated carbon for Type-I Langmuir. Synergetic coupling of methanol extraction and ultrasonic waves leads to totally recover the activated carbon adsorption capacity. The regeneration of used $\mathrm{AC}$ yielded up to $95 \%$ reactivation of the spent $\mathrm{AC}$ in the first run and up to $88 \%$ of activity recovered in the second run of the spent AC. The outcomes proposed that methanol extraction combined with ultrasonic treatment is potentially better than customary recovery technique because this treatment is less energy intensive; furthermore the adsorption capacity of spent $\mathrm{AC}$ was completely recovered. The reuse of exhausted activated carbon, which is difficult to manage, makes this waste economically valuable. The present study here indicates the feasibility to reuse the traditional charcoal tube air sampling which utilized for volatile compounds collection, rather to toss the tubes after just a single use.

\section{Acknowledgment}

Funding and laboratory facilities were provided by the Air Pollution Department and Chemistry of Natural and Microbial Products Department of the National Research Centre, 
Cairo, Egypt.

\section{Disclosure statement}

No potential conflict of interest was reported by the authors.

\section{References}

Allwar, Noor, A., \& Nawi, M. (2008). Textural Characteristics of Activated Carbons Prepared from Oil Palm Shells Activated with $\mathrm{ZnCl} 2$ and Pyrolysis Under Nitrogen and Carbon Dioxide. J Phys Sci, 19(2), 93-104.

Boehm, H. P. (1994). Some aspects of the surface chemistry of carbon blacks and other carbons. Carbon, 32, 759-764. https://doi.org/10.1016/0008-6223(94)90031-0

Brosillon, S., Manero, M. H., \& Foussard, J. (2001). Mass transfer in VOC adsorption on zeolite: experimental and theoretical breakthrough curves. Environ Sci Technol, 35, 3571-3575. http://dx.doi.org/10.1021/es010017x

Dabrowski, A. (2001). Adsorption from theory to practice. Adv. Colloid Interface Sci, 93, 135-224.

Eshtiaghi, M., Kuldiloke, J., \& Yoswathana, N. (2012). Deodorization of coconut oil using activated charcoal and charcoal regeneration. J Food Agric Environ, 10(3\&4), 178-181.

Guilane S., \& Hamdaoui, O. (2016). Regeneration of exhausted granular activated carbon by low frequency ultrasound in batch reactor. Desalin Water Treat, 57, 15826-15834. https://doi.org/10.1080/19443994.2015.1077350

Haydara, S., Ferro-Garciab, M. A., Utrillab, J., \& Jolya, J. (2003). Adsorption of p-nitrophenol on an activated carbon with different oxidations. Carbon, 41, 387-95. https://doi.org/10.1016/S0008-6223(02)00344-5

Kaya S., \& Kahyaoglu T. (2005). Thermodynamic properties and sorption equilibrium of pestil (grape leather). J Food Eng, 71, 200-207. http://dx.doi.org/10.1016/j.jfoodeng.2004.10.034

Li, W., Chen, J., Cong, G., Tang, L., Cui, Q., \& Wang, H. (2016). Solvent desulfurization regeneration process and analysis of activated carbon for low-sulfur real diesel. $R S C A d v, 6$, 20258-20268. https://doi.org/10.1039/C6RA01881E

Lv, G., Wu, L., Xiaoyu, Wang, X., Liao, L., Li, Z., \& He, W. (2012). Regeneration of Caramel Saturated Activated Carbon jointly by Microwave and Extractive Method. Int J Chem React Eng, 10, Article A88. https://doi.org/10.1515/1542-6580.3117

Ma, X., Peng, H., \& Zhang, X. (2016). Regeneration of nitrophenol loaded granular activated carbon and its effect on the surface properties of adsorbent. Desalin Water Treat, 57(53), 25494-25502. https://doi.org/10.1080/19443994.2016.1157523

Mohamed, E. F., Andriantsiferana, C., Wilhelm, A. M., \& Delmas, H. (2011). Competitive adsorption of phenolic compounds from aqueous solution using sludge based activated carbon. Environ Technol, 32, 1-12. https://doi.org/10.1080/09593330.2010.536783

Mohamed, E. F., Awad, G., Andriantsiferana, C., \& El-Diwany, A. (2016a). Biofiltration technology for the removal of toluene from polluted air using Streptomyces griseus. Environ 
Technol, 37(10), 1197-207. https://doi.org/10.1080/09593330.2015.1107623

Mohamed, E. F., El-Hashemy M. A., Abdel-Latif N. M, \& Shetaya, W. H. (2015). Production of sugarcane bagasse-based activated carbon for formaldehyde gas removal from potted plants exposure chamber. J Air Waste Manag Assoc, 65, 1413-1420. https://doi.org/10.1080/10962247.2015.1100141

Mohamed, E. F., Sayed, Ahmed S.A., Abdel-Latif, N. M, \& Mekawy, A. (2016b). Air purifier devices based on adsorbents produced from valorization of different environmentalhazardous materials for ammonia gas control. RSC Adv, 6, 57284-57292.

Quiñones, I., \& Guiochon, G. (1996). Isotherm Models for Localized Monolayers with Lateral Interactions. Application to Single-Component and Competitive Adsorption Data Obtained in RP-HPLC. Langmuir, 12(22), 5433-5443. https://doi.org/10.1021/la9603333

Stephen, B. S., Emmett, P. H., \& Teller, E. (1938). Adsorption of Gases in Multimolecular Layers. J Am Chem Soc, 60(2), 309-319. https://doi.org/10.1021/ja01269a023

US EPA (2012). An Introduction to Indoor Air Quality: Volatile Organic Compounds (VOCs) (EPA). http://www.epa.gov/iaq/voc.html. Accessed on 7-20-2015

US EPA (2014). Air Quality Trends (EPA). http://www.epa.gov/airtrends/aqtrends.html

Weisel, C. P., Alimokhtari, S., \& Sanders, P. F. (2008). Indoor air VOC concentrations in suburban and rural New Jersey. Environ Sci Technol, 42, 8231-8238. https://doi.org/10.1021/es8005223

Wheeler, A. J., Wong, S. L., Khoury, C., \& Zhu, J. (2013). Predictors of indoor BTEX concentrations in Canadian residences. Health Rep, 24, 11-17.

Ye, W., Little, J. C., Won, D., \& Zhang, X. (2014). Screening-level estimates of indoor exposure to volatile organic compounds emitted from building materials. Build Environ, 75, 58-66. https://doi.org/10.1016/j.buildenv.2014.01.018

\section{Copyright Disclaimer}

Copyright reserved by the author(s).

This article is an open-access article distributed under the terms and conditions of the Creative Commons Attribution license (http://creativecommons.org/licenses/by/3.0/). 